\title{
The research tree of the innovation ecosystems
}

\author{
Igor Chelak ${ }^{*}$
}

Ural Institute of Management - a branch of the RANEPA, 620144, 8 Marta Str., Ekaterinburg, Russia

\begin{abstract}
Innovative ecosystems continue to expand in the socio-economic sphere. The relevance and timeliness of the topic of ecosystems, insufficient elaboration of theoretical issues, incomplete methodological validity, high practical significance of the problems of management of the development of innovative ecosystems led to the choice of the purpose of this work: the development of a tree of research of innovative ecosystems. On the basis of the Schumpeter approach to innovation as the fundamental conditions of entrepreneurial activity, a hierarchy of scientific developments concerning the understanding of the essence of ecosystems and their models is built. The conceptual foundations of the ecosystem approach, universal ecosystem models and the typology of stakeholder configurations of the considered type of communities are highlighted.
\end{abstract}

\section{Introduction}

The tasks of the development of ecosystem theory, in particular, its stakeholder element, an integral element is the construction of a research tree of innovative ecosystems (IES). At the same time, the innovation ecosystem is presented broadly as a form of coordination of economic relations based on the principle of unity of the internal and external environment of the economic entity. This definition differs from the understanding of the innovation ecosystem as a structure for the creation and dissemination of innovations in their narrow interpretation.

The basis for the emergence of the ecosystem concept, which puts forward the need to identify a new form of coordination of economic activity, should be highlighted by the research of J. Schumpeter. For this author, innovation became the cornerstone concept in the program of studying economic patterns, innovation was seen as the foundation for the development of entrepreneurship. The ideas of the Austrian-American scientist about the influence of new combinations, changes in development [1], discoveries, inventions, developments as a basis for creating added value are now becoming relevant again. In the twenty-first century, competition has reached such a level that it seems impossible to maintain business without almost everyday innovations. Therefore, understanding innovation broadly, not only as a product, but also as a process, in terms of Eurostat [2], we

\footnotetext{
* Corresponding author: chelak@mail.ru
} 
are talking about an innovation ecosystem as the most adequate form of coordination of economic activity, combining the positive aspects of both markets and hierarchical and hybrid systems.

Having mentioned the systemic characteristics of the structure of the economy, it is necessary to note an important body of research on innovative systems [3], which provides a lot of material for the development of the ecosystem approach. However, the most important principle of consistency is the closeness of the community in relation to the external environment, which divides research programs of innovative systems and ecosystems along parallel paths.

The second component of the essence of innovative ecosystems is the connectivity of the environment and the studied core (be it a business structure, non-profit organization, network, cluster). Interaction in the ecosystem is abstracted from the division into external and internal environments. This property of relations, in all probability, was first noted in environmental studies, and in 1937 biologist Arthur Tensley introduced into scientific circulation the very concept of "ecosystem" regarding large biological communities in conjunction with the habitat in a limited area [4]. Gradually, in the natural sciences, the prefix "eco" (from Greek. oĩxos - dwelling, residence1) organically merged with the definition of the system. However, the use of the term "ecosystem" in economics began only in the 1990s.

\section{Results and Discussion}

Based on the results of the work, we will indicate publications that form a set of provisions of ecosystem economic analysis.

The experience of biology and ecology in the ecosystem description of relationships in the natural environment enabled the American economist James Moore to make a landmark discovery in 1993: the representation of business by analogy with ecosystems in nature, characterized by the extreme connectivity of players and the environment in economic and social relations. The article of this author "Predators and Prey: A New Ecology of Competition" [5] allowed to begin steps to resolve the problem of conceptual insufficiency in the study of the ecosystem phenomenon that already existed in reality at that time. Previously, the socio-economic branches of science and management practice operated with the terms "system" with the appropriate prefix (business system, economic, production, innovation), which did not adequately explain the fundamental connectivity of the environment and economic players. In the current century, the ecosystem approach has begun to actively gain adherents. So Ramenskaya L.A. found that "the number of scientific publications with the keywords "business ecosystem" in google.scholar has grown 6.5 times over the past 18 years" [6]. At the same time, this author, among other representatives of the scientific community, does not fully share the optimism regarding the widespread use of the term ecosystem [7].

It is advisable to defend the ecosystem approach. The very concept of "economy" is formed from the above word oixos. Oikos is a dwelling, a place where a person carries out life activities as an individual and collective agent. Where interaction with the world takes place, economic and social contacts are actually realized, both in real and virtual space. You can criticize J.Moore for excessive Darwinism of the concept. It can be justified by the fact that in nature, if we use the analogy of natural-environmental and social ecosystems, the basis

\footnotetext{
${ }^{1}$ The Great Russian Encyclopedia. https://bigenc.ru/biology/text/4927341
} 
of existence lies in the struggle for survival: both in competition with similar personalities, entities, and in the struggle with oneself. The latter is often the most difficult.

The following concept brings the researcher back to the first component of ecosystems: the need to constantly work with innovations, improvements, increments. If J. Moore the emphasis in the explanation of ecosystems was placed on interacting economic entities, then in the concept of H. Etzkowitz and L. Leydesdorff "triple helix" the vision of the ecosystem expands: universities and the government are adjacent to the economic agents themselves [8]. As a result of scaling the ecosystem model, the subject and complexity of the research program increases dramatically.

In the paradigm under consideration, the knowledge component of the phenomenon under study begins to manifest itself openly, where the role of the innovation subsystem is given primarily to universities as centers for assembling new ideas, developing competencies, and primary testing of knowledge. In addition, if the economic environment has traditionally been filled primarily with business structures, then in modern capitalism the state plays an important role as an institutional subject, setting, coordinating, controlling agent, as an adjuster and translator of the will of society. Such a broad role of the state in the triple helix led to the evolution of the concept. Further development of the ecosystem theory was based on increasing the number of turns of the spiral, by including such objects as the natural environment [9] and civil society [10] in the review.

An important component of the research tree is the works of M. Jacobides, who announced a shift in the focus of economic analysis to meso-communities, including ecosystems [11].

By analogy with the theory of ecosystem evolution in biology, which focuses on the patterns of development of the entire spectrum of communities, rather than individual species, Michael Jacobides considers medium-level communities to be the key economic agents. They are located between base agents, such as households and firms, and communities of macroeconomic order. Thus, the main interactions occur between these poles, where contracts, transactions, exchange of resources, and information flows are concentrated. Studies of firms do not give a complete picture of economic transactions, they are not able to organize stochastic operations, discrete relationships into a certain environment with conditional boundaries. The concept of ecosystem interactions is designed to fulfill this task.

Also, a significant area of research is the division of the ecosystem space into knowledge and business subsystems [12]. Hence, economic analysis focuses on alternative strategies for ecosystem development - mainly commercial or research.

The next milestone of the research program is the statement on the recognition of ecosystem analysis as part of the strategic [13]. Ecosystem analysis really has similar tools when it comes to the ecosystem as a kind of core in conjunction with the environment. The terms external environment and internal environment are included in the tools of strategic management. But if, within the framework of strategic analysis, the external environment in relation to the analyzed economic entity is alien, admits, by analogy with the military art, from where the term "strategy" came from, exclusively protecting one's own interests, expansion, unfriendly actions in relation to elements of the external environment, then the ecosystem approach includes the external environment in the orbit of trust.

Within the framework of strategic management, it is necessary to talk about cooperation with caution, therefore it is necessary to allocate the ecosystem approach to a separate niche and recognize ecosystem management as a separate, independent type of impact. 
For a more complete understanding of the research tree, from the entire set of existing models of innovative ecosystems for the tasks of our work, we will highlight several fundamentally different from each other and suitable for the description of the author's vision of the innovation ecosystem. The latter implies a broad understanding of the innovation component of the type of communities under study as a desire for constant and effective innovations, changes, in contrast to the narrow interpretation of innovations as embedded results of special research $(\mathrm{R} \& \mathrm{D})$. The need for this assumption is dictated by the lack of terminological uniformity in economic research.

We will conceptually identify a number of areas of ecosystem research by indicating the format of the model of the phenomenon under consideration.

1. Universal model. If the subsequent ecosystem models appeal to a certain aspect of socio-economic relations and technological capabilities, then the distinctive feature of the first model of describing the ecosystem phenomenon is universality. A number of authors try to comprehend the ecosystem in its full deployment as a set of the maximum possible number of phenomena, including objects, processes, projects, environments in the subject of study $[14,15]$. The multidimensionality of ecosystems allows us to absorb all the complexity of what is happening in the socio-economic world, which justifies the thesis of the development in the future of the economy not of organizations, but of the economy of ecosystems, when any economic relations can be described in terms and principles of the ecosystem approach.

2. Network model. The ecosystem is interpreted by a number of authors [16] in terms of a network approach: the interaction of peer-to-peer organizations, horizontal communication, hierarchy minimization, predominantly single-industry affiliation of network segments, comparable scale of economic activity of companies. The network concept helps to better understand ecosystems with these characteristics, and is not intended to study in detail the interaction of small companies with communities of a different configuration and nature. The essence of the approach can be expressed by the following quote: "Thanks to the development of Internet technologies, numerous small groups can become the main cells of the economy, uniting producers, consumers and intermediaries into flexible networks" [16, p.29].

3. The entrepreneurial model [17] is responsible for the practical aspect of ecosystem research with an emphasis on the development of the innovation component proper in its narrow sense. In this model, the emphasis is placed on supporting the development of research, inventive, entrepreneurial competencies, business interactions with the support of relevant development institutions, incubators, organizations specializing in the acceleration of new technological productions, startups. The model under consideration is more intended for studying an emerging, developing business or local projects. With this approach, the innovation ecosystem includes startups, support agencies, and major players interested in further acquiring a developing business.

4. The digital model is one of the most popular models in the current conditions. The need for its allocation is based on the rapid and broadest development of the information, knowledge economy, on the one hand, and on a technological breakthrough, including in the field of hardware and software infrastructure of the digital economy [18], allowing to build almost dimensionless platforms in a short time. At the same time, the technological component creates both many opportunities and a number of risks for digital platforms. If we are talking about scaling, for example, a consumer digital platform, the main characteristic of which is the principle of rapid "entry-exit" at insignificant costs of consumers and suppliers, then its potential rapid growth may be replaced by a sharp decline. The digital platform is capable of instantly collapsing banally with a legislative or malicious 
shutdown, blocking of ecosystem servers. In a competitive industry (transportation platforms, rental housing), indeed, if for a number of reasons the work of the platform is limited, its customers, service providers are able to move into the orbits of "neighboring" competitive ecosystems with minimal losses. The designated configuration of ecosystems, thus, will determine the growth of transaction and transformation costs to protect "from the law", to guarantee the operability of applications, equipment, networks. The infrastructure component of ecosystems is a vital characteristic that shows how vulnerable modern business models are in today's conditions.

5. The need to highlight the entrepreneurial social ecosystem [19] is seen in the trends of shifting the goals and objectives of public practice, research programs, corporate responsibility [20]. If in the segment of goods and services of traditional consumer demand, the added value created is declared as a priority in the activities of "classical entrepreneurship", then social entrepreneurship is primarily focused on the subject of activity (support for vulnerable groups of the population, educational, cultural, environmental projects), and not the financial flow. Hence, as part of the development of social entrepreneurship, new markets are being created, and unique approaches to financing activities (crowdfunding, fundraising) are being spread, which in turn is effective when using ecosystem principles of interaction. With a general similarity with traditional entrepreneurship, the differences between ecosystems of social practices can be concluded in the elemental content of ecosystems, the core component, and the diversity of network relations. The purpose of identifying such ecosystems is determined by the presence of increased interest in the social component of business and the wide possibilities of applying an ecosystem approach to the analysis of activities in the field under consideration.

6. Stakeholder model. When reviewing the types of ecosystem models, it should be noted that the complexity of the phenomenon under consideration determines the need for crossmodeling. For example, Valdez-de-Leon's studies consider the synthesis of both network model and digital features in the ecosystem genesis [21]. Such an intersystem characteristic also applies to the group of stakeholder ecosystem models that we are most interested in within the framework of this study. Studies by many authors are devoted to their individual features. In the graphic description of the development of the research of the IES, the work of Lütjen and co-authors is highlighted as an example of scientific and practical research focused on the role of stakeholders in the development of the innovative component of ecosystems [22].

A further review is devoted to the disclosure of the stack of stakeholder models.

The theory and practice of ecosystem analysis should represent ecosystems in the unity of the core and the environment - stakeholders. Accordingly, the urgent task is to set up the research apparatus, the formation of management tools focused on the analysis of the influence of stakeholders, their interaction with the core of the ecosystem. Transactions within the IES occur between unique organizations, agents and companies. Management decisions within the framework of ecosystem formation should be focused on significant stakeholders. The above interpretation is based on everyday, constant and discrete communications between specific individuals, and already within the framework of this concept, we propose to identify a line of proper stakeholder models of eco-ecosystems. This line helps to highlight the differences in the nature and nature of ecosystem interactions, depending on the characteristics of a particular IES.

1. Platform ecosystem. The pool of stakeholder models of innovation ecosystems includes digital, platform ecosystems described within the framework of transactional tools 
with an emphasis on the presence of multiple stakeholders in the platform, primarily suppliers and consumers [23].

2. An expanding ecosystem. Highlighting growth as a priority strategy for the development of the innovation ecosystem entails the inclusion of an expanding ecosystem in the structure of the stakeholder models of the IES [24]. The mission of such a community is seen in the possibility of maximizing the number of stakeholders, universalizing relations. Depending on the management and research tasks, more and more areas of economic reality can be included in the orbit of the expanding ecosystem, which brings the concept under consideration closer to the triple helix model. Borrowing the terminology of the latter, we point out that the deployment of the ecosystem spiral helps to show the possibilities of filling, expanding communities with new elements, stakeholders. If we look at economic interactions starting from the basic level, within the household, then further expansion of the viewing angle involves additional segments of the spiral into the primary ecosystem, leading to the conclusion made by Kleiner [25] about the representation of the entire economy as a large ecosystem.

3. The core ecosystem. Returning to the spiral model, recently there has been a growing interest in describing ecosystems depending on the characteristics of organizations acting as the core, coordinator of the IES. Most often, a research program includes universities as a central element of the ecosystem. As an example, the work of K. Brito [26] is given, while almost any type of modern communities can play a leading role in the ecosystem: production, research, financial, social orientation, development institutions. This provides ample opportunities for the ecosystem approach to search for unique characteristics of the core ecosystems, depending on their main component.

4. Smart ecosystem. In this model, the emphasis is placed on large territorial communities (district, city, region). The article cited here [27] describes the ecosystem of not just a specific settlement, but shows the possibilities of an ecosystem approach to describe the community in terms of the concept of a smart city, which includes stakeholders of the public, managing, economic segment of the territory, which makes it possible to present the ecosystem as a projection of a smart community-a region in which, regardless of the sectoral characteristics of the players, interactions are regular and mutually beneficial. The model also describes in detail the technological capabilities of smart communities, which, together with the description of ecosystem interactions, shows the synergetic potential of smart ecosystems.

5. Multi-factor network. This concept also belongs to the stack of stakeholder models. A study [28] is given as a reference article, which deserves the following comment. Previously, a network approach to a peer-to-peer ecosystem, horizontal, was described. If we consider stakeholder interactions not only in the network, but also in the regional and institutional context, the ecosystem under study will appear as a multidimensional structure. The understanding of the economy is not based solely on the segmentation of industries, which turns the model into a convenient scheme of initial analysis, but requires additional tools, among which you can include a model, in particular, smart ecosystems.

6. Semi-open model of the IES. Da Silva's work with co-authors [29], when identifying the stakeholder component of the ecosystem, divides stakeholders into internal and external stakeholders, which simplifies the analysis, but leads away from understanding the nature of the ecosystem as a unity of internal and external environment. Therefore, when solving research tasks, we saw the need to move away from the concept of strategic management in the ecosystem, to find an alternative, promising tools, features that could be described as ecosystem. 
7. The author's unitary ecosystem model $[30,31]$ is built taking into account previous studies (connections are graphically highlighted in the figure), focuses on the equality of stakeholders to ensure effective stakeholder interactions, eliminating the division of the environment into internal and external. We insist on the need to implement cooperation and coordination requests, the ESG concept, the principles of the economy of trust, proven game theory and socio-economic ratings of developed countries into the research program for studying ecosystems. The open development of a digital, platform, ecosystem economy, which is not suppressed by political decisions, entails the elimination of most institutional traps, involves the elimination of opportunism and information asymmetry, reducing transaction costs, eliminating the possibilities of negative selection.

The results of building the research tree are shown in Figure 1.

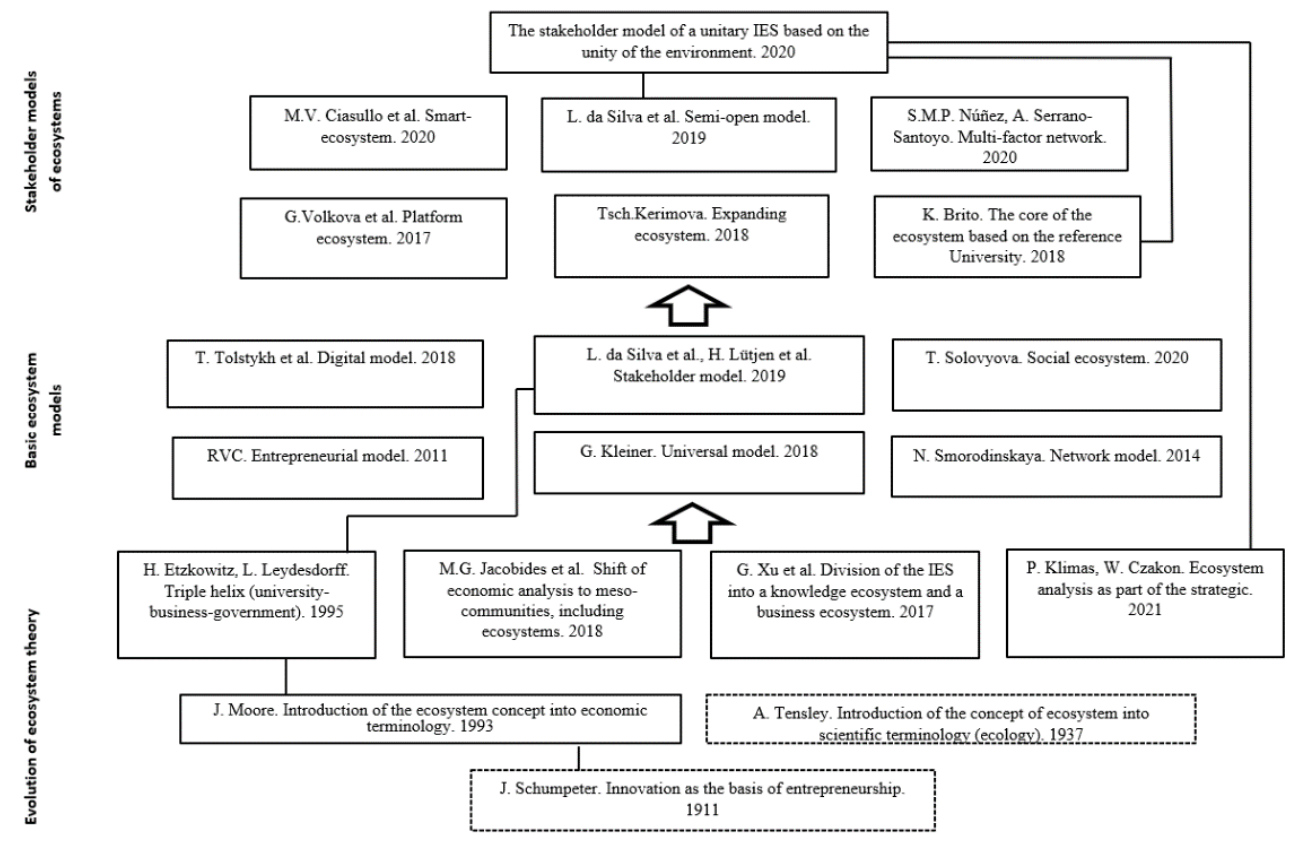

Fig. 1. The Research Tree of the Innovation Ecosystems.

Source: authors' development

\section{Conclusions}

Based on the results of the work carried out, a tree of research on innovative ecosystems is proposed. The significance of the obtained results lies in the development of a theoretical apparatus for describing, analyzing, and evaluating the analyzed economic phenomenon.

The results of the study systematize concepts regarding the characteristics of ecosystems, the principles of their construction and development. Based on the features of innovative ecosystems highlighted in the above concepts, it is possible to compare ecosystems with other forms of economic coordination - firms, markets and hybrid forms. 


\section{References}

1. J. A. Schumpeter, The Theory of Economic Development (Harvard University Press, 1934)

2. OECD/Eurostat, Oslo Manual: Guidelines for Collecting, Reporting and Using Data on Innovation, 4th Edition, The Measurement of Scientific, Technological and Innovation Activities, OECD Publishing, Paris/Eurostat, Luxembourg (2018)

3. A. Suominen, M. Seppänen, O. Dedehayir, A bibliometric review on innovation systems and ecosystems: a research agenda, European Journal of Innovation Management, 22 (2) (2019)

4. V. I. Danilov-Danilyan, Ecosystem is one of the most important fundamental concepts of modern science, Ecosystems: ecology and dynamics, 1 (1) (2017)

5. J. F. Moore, Predators and Prey: A New Ecology of Competition (Reprint), Harvard Business Review, 71 (3) (1999)

6. L. A. Ramenskaya, Review of approaches to the study of business ecosystems, Bulletin of the Altai Academy of Economics and Law, 12-2,153-158 (2019)

7. L. A. Ramenskaya, Application of the concept of ecosystems in economic and managerial research, The Manager, 11 (4) (2020)

8. H. Etzkowitz, The Triple Helix of University - Industry-Government Relations: A Laboratory for Knowledge - Based. Economic Development, EASST Review, 14 (1995)

9. E. G. Carayannis, T. D. Barth, D. F. Campbell, The Quintuple Helix innovation model: global warming as a challenge and driver for innovation, Journal of Innovation and Entrepreneurship, 1 (2) (2012)

10. E. Carayannis, E. Grigoroudis, Quadruple Innovation Helix and Smart Specialization: Knowledge Production and National Competitiveness, Foresight and STI Governance, 10 (1) (2016)

11. M. G. Jacobides, C. Cennamo, A. Gawer, Towards a theory of ecosystems, Strat Mgmt J., 39 (2018)

12. G. Xu, Y. Wu, T. Minshall, Y. Zhou, Exploring innovation ecosystems across science, technology, and business: A case of $3 D$ printing in China, Technological Forecasting and Social Change, 136 (2017)

13. P. Klimas, W. Czakon, Species in the wild: a typology of innovation ecosystems, Review of Managerial Science (2021)

14. G. Kleiner, Industrial ecosystems: a look into the future, Economic Revival of Russia, 2 (56) (2018)

15. V. Karpinskaya, Ecosystem as a unit of economic analysis. Systemic Problems of Domestic Mesoeconomics, Microeconomics, Enterprise Economics: Materials of the Second Conference of the Department of Modeling of Production Facilities and Complexes of the CEMI RAS, 2, (2018)

16. N. Smorodinskaya, Network innovation ecosystems and their role in dynamization of economic growth, Innovations, 7 (189) (2014)

17. Venture investments and the ecosystem of technological entrepreneurship. Collection of articles, Publishing House of the Russian Venture Company (2011) 
18. T. Tolstykh, E. Shkarupeta, L. Gamidullayeva, Digital innovative production based on the formation of an ecosystem of services and resources, Economics in industry, 11 (2) (2018)

19. T. Solovieva, Theoretical aspects of the formation and development of regional socioinnovative ecosystems, Bulletin of the NGIEI, 3 (94) (2019)

20. A. Armstrong, Ethics and ESG, Australasian Accounting, Business and Finance Journal, 14 (3) (2020)

21. O. Valdez-De-Leon, How to Develop a Digital Ecosystem - a Practical Framework, Technology Innovation Management Review, 9 (8) (2019)

22. H. Lütjen, C. Schultz, F. Tietze, F. Urmetzer, Managing ecosystems for service innovation: A dynamic capability view, Journal of Business Research, Elsevier, 104 (2019)

23. I. Volkova, A. Yakovleva, Diagnosis of the conditions for the development of innovative ecosystems in the energy sector, Innovations, 10 (228) (2017)

24. Tcsh. Kerimova, The use of the stakeholder approach in determining the directions of innovative development of the company, Accounting. Analysis. Audit, 5 (4) (2018)

25. G. Kleiner, Ecosystem economics: step into the future, Economic revival of Russia, 1 (59) (2019)

26. C. Brito, Promoting the creation of Innovation Ecosystems: the case of the University of Porto - Letter From Academia, Journal of Innovation Management, 6 (3) (2018)

27. M. V. Ciasullo, O. Troisi, M. Grimaldi et al., Multi-level governance for sustainable innovation in smart communities: an ecosystems approach, Int Entrep Manag J., 2 (2020)

28. S.M.P. Núñez, A. Serrano-Santoyo, Multi-Actor Network Perspective: CaliBaja an emergent binational innovation ecosystem, Technology Innovation Management Review, 10 (1) (2020)

29. L. M. da Silva, C.C. Bitencourt, K. Faccin, T. Iakovleva, The Role of Stakeholders in the Context of Responsible Innovation: A Meta-Synthesis. Sustainability, MDPI, Open Access Journal, 11 (6) (2019)

30. E. Popov, V. Simonova, I. Chelak, Stakeholder model of the innovation ecosystem of the region, Innovations, 6 (260) (2020)

31. E. Popov, V. Simonova, I. Chelak, Systematization of factors of development of the innovative ecosystem of the enterprise, Management issues, 4 (2021) 